\title{
BOX 3 Seamount Discovery Tool Aids Navigation to Uncharted Seafloor Features
}

By David T. Sandwell and Paul Wessel

Wessel et al. (2010) highlight the need for a systematic mapping of seamounts in ocean basins. They estimate that 100,000 or $90 \%$ of the seamounts greater than $1-\mathrm{km}$ tall are unobserved by either ship soundings or satellite gravity. There are two reasons why most of these relatively large, predicted seamounts remain uncharted. First, satellite-derived gravity is only able to reliably measure seamounts that are more than $2-\mathrm{km}$ tall, although smaller seamounts can be detected (Wessel, 2001). Second, the freely available ship sounding data collected during the past 50 years only covers $10 \%$ of the seafloor at the 1 -minute resolution needed to detect these 1-km and taller seamounts (Becker et al., 2009). Based on current trends in seafloor mapping, the rate of seamount discoveries is not likely to change significantly because modern research surveys are focused on particular areas of high scientific interest such as mid-ocean ridges, continental margins, and subduction zones. This exploration strategy has resulted in gaps in remote areas of up to $600 \mathrm{~km}$ by $300 \mathrm{~km}$. As Figure 1 shows, more than $50 \%$ of the seafloor lies more than $9.5 \mathrm{~km}$ from the nearest ship sounding. This sparse coverage, combined with a relatively

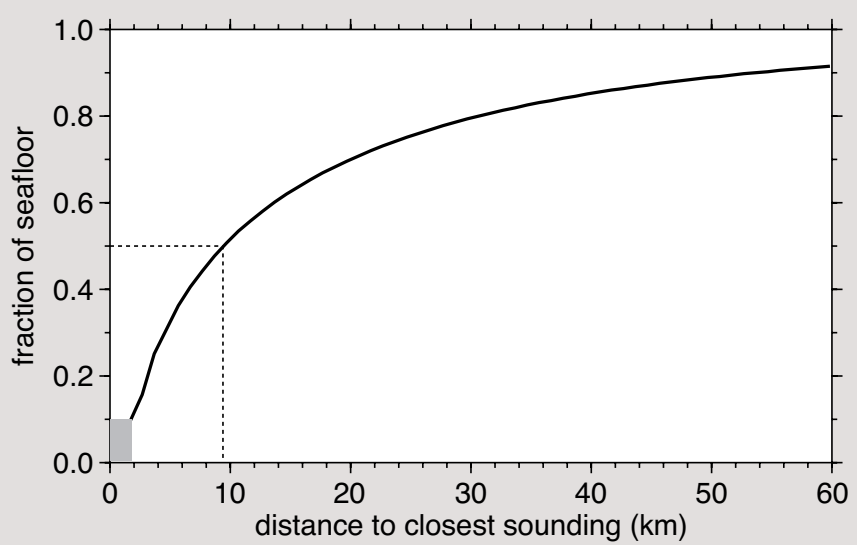

Figure 1. Fraction of seafloor as a function of distance to the closest sounding (Walter, H.F. Smith, National Oceanic and Atmospheric Administration, pers. comm., 2009). The grey box marks the $10 \%$ of seafloor that is charted at 1-minute resolution. Dashed lines show the $50 \%$ of seafloor that lies more than $9.5 \mathrm{~km}$ from a sounding. Note that $10 \%$ of the seafloor is more than $60 \mathrm{~km}$ from a depth sounding. random spatial distribution of seamounts, results in the situation today where there are even $3-\mathrm{km}$ and $4-\mathrm{km}$ tall seamounts that have not been surveyed by ships.

In order for researchers to plan surveys of these remote areas, they must first be able to determine which areas are not charted, and then be able to determine the likelihood of observing a seamount of interest in a particular location. If this information were readily available, then scientists, ship captains, and even recreational sailors could make important discoveries with minimal cost and effort. Consider the UNOLS fleet of seven large research vessels, each carrying deep-ocean multibeam sonar systems. Each ship spends about 200 days a year at sea, and approximately $15 \%$ of that ship time is used to transit from a port to the general survey area. In addition, as much as $50 \%$ of a typical regional survey is spent moving among sites (Stephen Miller, Scripps Institution of Oceanography, pers. comm., 2009). The transits usually follow a great circle route to minimize ship time, but in many instances this track results in repeated surveys of the same seafloor. In these cases, minor diversions from this great circle route could be used to survey new areas, using little or no extra ship time. Thus, we propose that this transit time could be optimized to chart seamounts.

We have developed an easy-to-use survey tool based on Google Earth software to be installed on research and other vessels having deep-water ( $>3000 \mathrm{~m}$ ) echosounders. The tool requires only a laptop computer, a handheld GPS (or more accurate shipboard GPS when available), and the current seafloor mapping data, as described below. This tool will enable scientists and sailors to plan surveys of uncharted seafloor and discover major undersea features with little or no impact on their scheduled activities. The design of a survey will depend on the available ship time and the size of the feature. A single profile or swath over the summit has the highest priority. Additional surveying will depend on the distribution of prior sounding data as well as the shape of the features as predicted from satellite gravity. Figure 2 is an example map of a large region in the western Pacific. The contour interval is $500 \mathrm{~m}$ and the thick contour is

David T. Sandwell (dsandwell@ucsd.edu) is Professor, Scripps Institution of Oceanography, University of California at San Diego, La Jolla, CA, USA. Paul Wessel is Professor, Department of Geology and Geophysics, School of Ocean and Earth Science and Technology, University of Hawai i, Honolulu, HI, USA. 


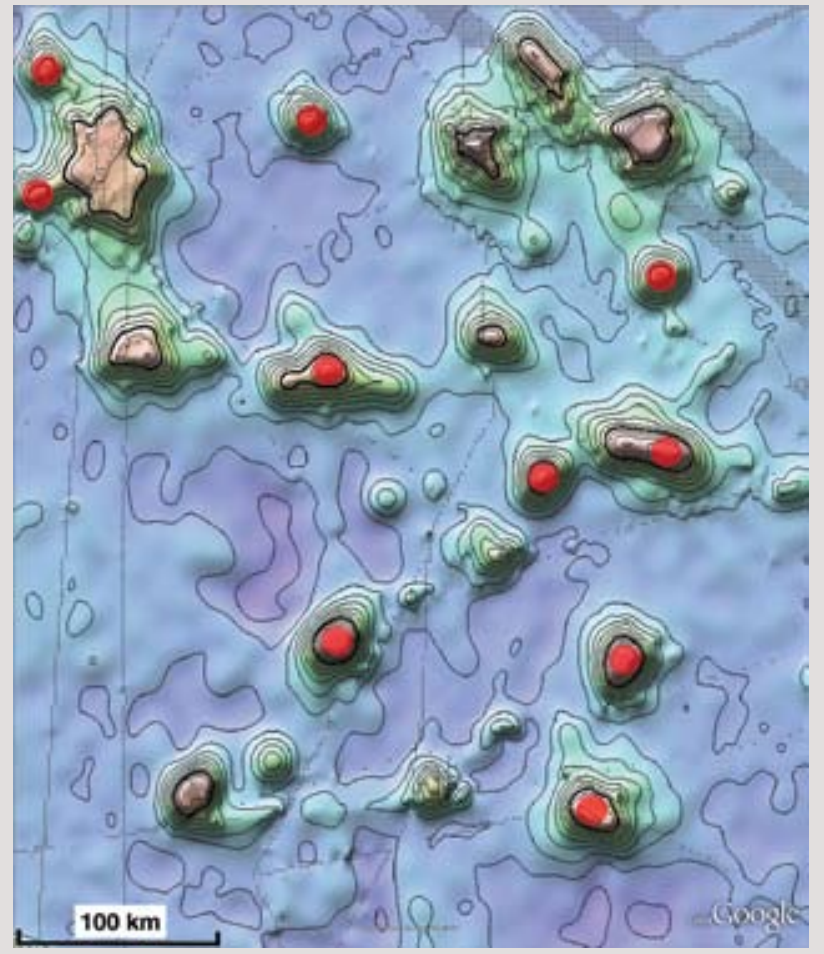

Figure 2. Example bathymetry overlay available as part of the Seamount Discovery Tool. Contours show depth based on the 1-minute version 12 of the Smith and Sandwell (1997) bathymetric prediction. Black dots show the soundings used as depth constraints (Becker et al., 2009). Red dots show 10 uncharted seamounts more than 3-km tall. The overlays were made using new capabilities of the Generic Mapping Tools (relevant code: img2google).

$-2000 \mathrm{~m}$. The small black dots show locations of existing ship soundings. Note the 10 seamounts (red dots) predicted to be more than 3000-m tall based on satellite gravity. These targets for exploration are very poorly sampled by existing ship soundings. This area is remote, and it is unlikely there will be a survey ship transiting the area soon.

For a more likely example, we consider the track between San Diego, California, and Oahu, Hawai' $i$, which has been surveyed multiple times with both single- and multibeam sonars. In this case, we consider three routes to Hawai $i$. The great circle route is $4180 \mathrm{~km}$, takes 188.2 hours at a typical cruise speed of 12 knots, and covers no new territory. A second route that visits 12 unsurveyed seamounts is $4300.1 \mathrm{~km}$. This route results in a $2.8 \%$ increase in time and fuel costs, which could be significant. A third route that visits seven seamounts follows a great circle from San Diego to way point 8 and then follows the seamount trackline. This path is $4189.7 \mathrm{~km}$ long, which is only a $0.23 \%$ increase

\section{SETUP FOR REAL-TIME GPS WITH GOOGLE EARTH}

Hardware

- Computer (PC or Mac) with USB port

- Garmin GPS Map 60 (\$249.99) or existing shipboard GPS with NEMA output

- USB Cable (\$14.99)

- External antenna (\$31.49) (note that many GPS receivers will work with Google Earth: http://earth. google.com/intl/en_uk/userguide/v5/ug_gps. html\#supported)

Software and Data

- Google Earth (V5.0) software

- Bathymetry overlays in kmz format (http://topex.ucsd.edu)

- Start Google Earth, go to Tools > GPS

- Realtime Garmin PVT, Trackpoint import limit 100, Polling interval $10 \mathrm{sec}$. (may need to cycle GPS power and trash the realtime entry in the "Temporary places" folder)

in distance/time. This increase is probably insignificant in terms of cost but potentially highly significant in terms of the resulting science. An additional benefit from performing this type of transit survey is that the responsible parties aboard the ship would become engaged in the discovery, monitor the sonar, and seek assistance when the data quality deteriorates.

Widespread adoption of this plan will require: support of the scientific community and ship operators in adopting the charting of new seafloor as an ongoing science priority or requirement; installation of the equipment and software on each research vessel; and, finally, a way to update the global bathymetry maps so other vessels would not repeat the more recent surveys. The NOAA Ship Okeanos Explorer, which is dedicated to exploring the world ocean (see Box 5 on page 88 of this issue [Hammond et al., 2010]), could use this tool for seamount exploration. Perhaps the actual implementation of the survey is best performed by the captain of each vessel in consultation with a chief scientist 


\section{BOX 3 | Continued...}

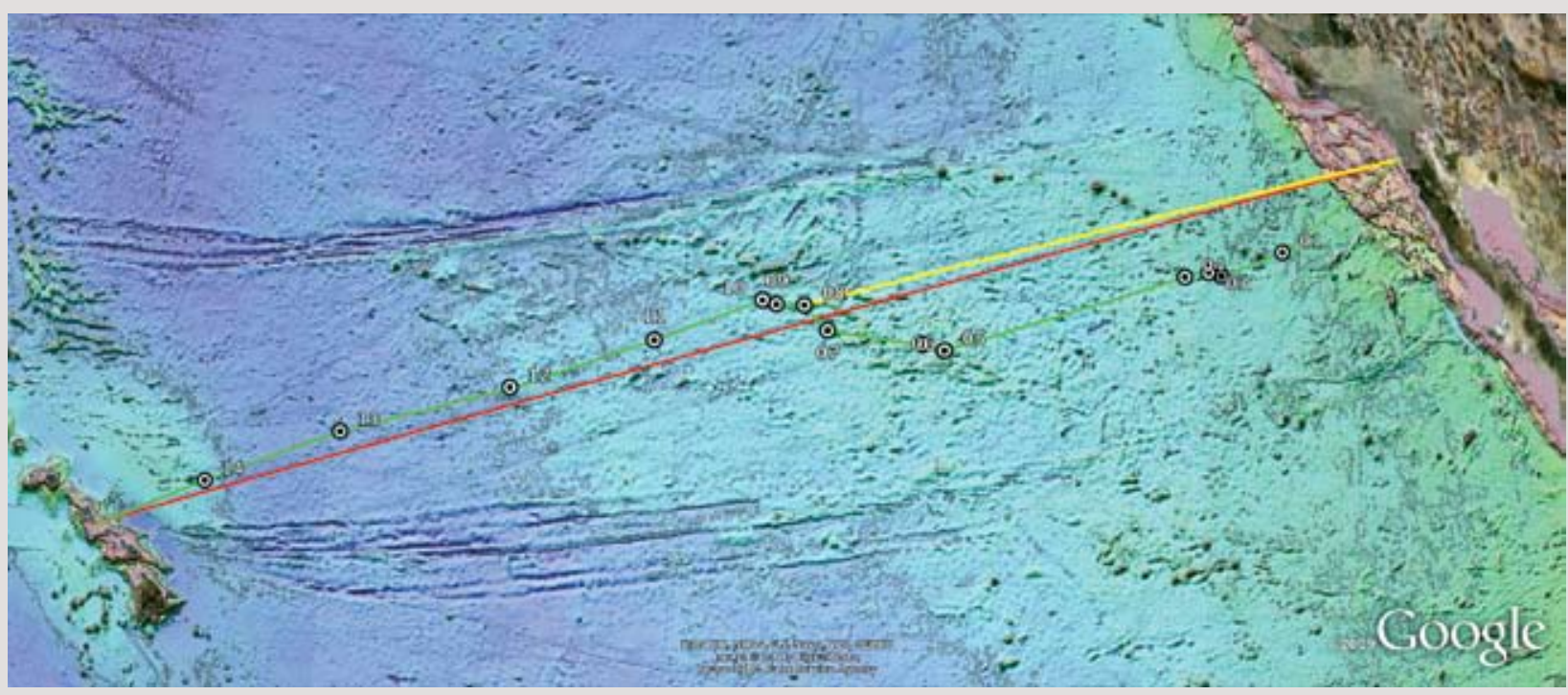

Figure 3. Possible transit routes from San Diego, California, to Oahu, Hawai' i, displayed in Google Earth along with the bathymetric overlay. The most direct route is a great circle (red line). The numbered way points mark positions of 12 uncharted seamounts $>1-\mathrm{km}$ tall based on bathymetry predicted from satellite gravity. Following all the way points (green line) increases the path length by $2.8 \%$. Following way points $8-14$ (yellow, then green) increases the path length by only $0.23 \%$, and seven large seamounts would be visited.

(if available) and marine operations. Captains of research vessels strive to provide safe and optimal conditions for collecting high-quality science data, and we believe they would be eager to adopt this tool as long as they have flexible control over the transit cruise plan. Data would flow through the normal channels to the US National Geophysical Data Center where it would ultimately be added to the global database and then used to update the bathymetry overlays. As the technology for real-time display of the bathymetry evolves, the technology aboard the ships should be upgraded.

\section{REFERENCES}

Becker, J.J., D.T. Sandwell, W.H.F. Smith, J. Braud, B. Binder, J. Depner, D. Fabre, J. Factor, S. Ingalls, S.-H. Kim, and others. 2009. Global bathymetry and elevation data at 30 arc seconds resolution: SRTM30_PLUS. Marine Geodesy 32(4):355-371, doi:10.1080/01490410903297766.

Hammond, S., J. McDonough, and C. Russell. 2010. Box 5: The NOAA ship Okeanos Explorer: New ways for exploring the ocean. Oceanography 23(1):88-89.

Smith, W.H.F., and D. Sandwell. 1997. Global seafloor topography from satellite altimetry and ship depth soundings. Science 277:1,956-1,962.

Wessel, P. 2001. Global distribution of seamounts inferred from gridded Geosat/ERS-1 altimetry. Journal of Geophysical Research 106(B9):19,431-19,441.

Wessel, P., D.T. Sandwell, and S.-S. Kim. 2010. The global seamount census. Oceanography 23(1):24-33. 